\title{
Complexity of Medication Regimen Prescribed on Hospital Discharge in Paediatric and Geriatric Patients with Psychiatric Disorder
}

\author{
Ashwin Kamath ${ }^{1}$, Priyanka Kamath ${ }^{1 *}$, Sanjay Hadigal ${ }^{2}$, Mukta N Chowta ${ }^{1}$, Pemminati Sudhakar $^{3}$ \\ 'Department of Pharmacology, Kasturba Medical College, Manipal University, Mangaluru - 575001, INDIA. \\ ${ }^{2}$ Medical Advisor, Medical Affairs, Mylan, Bengaluru, Karnataka, INDIA. \\ ${ }^{3}$ Department of Pharmacology, American University of Antigua College of Medicine, Coolidge, ANTIGUA.
}

\begin{abstract}
Background: Prescribing multiple medications to a patient increases the complexity of the treatment regimen and, thereby, the chances of noncompliance and adverse effects. The phase of discharge from the hospital is a critical period wherein the patient and/or the caretakers have to assume the responsibility of taking/providing the medications as directed by the physician. The objective of this study is to assess the complexity of medication regimen prescribed on hospital discharge to pediatric and geriatric patients with psychiatric disorders using the Medication Regimen Complexity Index (MRCI) instrument. Method: A descriptive, case record based study was conducted. The complexity of the hospital discharge prescriptions in pediatric and geriatric psychiatry patients was measured using the Medication Regimen Complexity Index instrument. Results: Of the 90 discharge prescriptions studied, 40 belonged to pediatric age group. The median number of drugs that each patient received was two in the pediatric group and five in the geriatric group $(p<0.001)$. The median $\mathrm{MRCl}$ score was significantly higher in the geriatric group (15.5) compared to the pediatric group (7.5) $(p<0.001)$. Gender difference was seen with significantly higher scores in geriatric men. Conclusion: While polypharmacy is of concern across all age groups, our study showed that the medication regimen complexity in significantly higher in the geriatric age group. Special attention
\end{abstract}

is required in case of geriatric patients to simplify their medication regimen at the time of hospital discharge in order to ensure better compliance.

Key words: Age, Gender, Medication regimen complexity, Polypharmacy, Psychotropics.

Key messages:

1. Medication regimen complexity index is significantly higher in geriatric patients with psychiatric morbidity.

2. Gender difference is seen in the medication regimen complexity.

3. Prescriptions with the same number of drugs can have different medication regimen complexity scores.

Correspondence :

Dr. Priyanka Kamath., M.D., Department of Pharmacology, Kasturba Medical College, Manipal University, Mangaluru - 575001, Karnataka, INDIA.

Phone:+91-824-2422271

Email: priyanka.kamath@manipal.edu

DOI: 10.5530/jyp.2017.9.79

\section{INTRODUCTION}

Polypharmacy in the treatment of psychiatric disorders in not uncommon. ${ }^{1-4}$ Many a time's multi-drug prescription is clinically indicated. However, using two or more medications to treat the same condition, or using two or more drugs belonging to the same class, or using two or more drugs with similar actions, is accepted as polypharmacy. ${ }^{5,6}$ Prescribing multiple medications to a patient increases the complexity of the treatment regimen and the chances of adverse effects. This could have an adverse impact with respect to the compliance to treatment. Patients often find it beyond their comprehension to manage their medication schedules and advice. ${ }^{7,8}$ The phase of discharge from the hospital is a critical period wherein the patient and/or the caretakers have to assume the responsibility of taking/providing the medications as directed by the physician. A study conducted in patients immediately following hospital discharge found that up to $7 \%$ of the patients had prescription handling issues as early as within a week of discharge. ${ }^{8}$ However, this percentage varies considerably depending on the disease and the treatment setting.$^{9,10}$ The presence of psychiatric morbidity poses an additional challenge with regard to adherence to prescribed medication regimen. The complexity of medication regimen can be quantified using the Medication Regimen Complexity Index (MRCI) instrument. MRCI is a 65 -item instrument that can be used to quantify medication regimen complexity at the patient level. ${ }^{11}$ It can be considered both reliable and valid to assess, and can be applied for practice as well as research. ${ }^{11-13}$ The aim of our study was to assess the complexity of medication regimen prescribed on hospital discharge in pediatric and geriatric patients with psychiatric disorders using the Medication Regimen Complexity Index (MRCI) instrument. We also intended to study the difference between the MRCI scores with regard to gender.

\section{MATERIAL AND METHODS}

This descriptive, case record study was conducted at a South Indian tertiary care University teaching hospital which caters to the healthcare needs of a large population including from the neighboring states. Ethical approval was obtained from Institutional Ethics Committee, Kasturba Medical College, Mangalore, prior to initiation of the study. Data was collected from the patient case record forms based on the ICD-10 disease coding (International Statistical Classification of Disease and Related Health Problems, Tenth revision, ICD-10, F00-F99). No personally identifiable data was recorded. The data of drugs prescribed during discharge from the hospital was collected from psychiatric inpatient records in the pediatric age group ( $\leq 18$ years of age) and the geriatric age group ( $\geq 65$ years of age), who were admitted to the hospital over a period of one year. Data collection for the geriatric age group was subsequently extended to one more year due to inadequate data sample. Data of

This is an open access article distributed under the terms of the Creative Commons Attribution-NonCommercial-ShareAlike 4.0 License, which allows others to remix, tweak, and build upon the work non-commercially, as long as the author is credited and the new creations are licensed under the identical terms. 
patients discharged from the hospital without a drug prescription was not included in the study. Data collected included age, gender, total number of drug(s) prescribed on hospital discharge, and the details of drug(s) prescribed (formulation, frequency of administration, instruction to patient). Polypharmacy was defined as prescription of two or more medications. The complexity of the prescription information collected was scored using the MRCI. ${ }^{11}$

The MRCI is divided into three different sections, which contribute to the final score based on the weight of the tasks in the medication regimen. Section a covers dosage forms, Section B scores the dosing frequency and Section $\mathrm{C}$ covers the additional instructions given such as to crush or dissolve a tablet, advice in relation to food intake, etc. Each section has its own score, and the final complexity score is the sum of the section subtotals. The minimum MRCI score is 1.5 . This represents a single tablet or capsule to be taken once a day on an as-needed basis. There is no established maximum as the score increases with the number of medications. ${ }^{11,12}$

The data was analyzed using SPSS version 11.5 (IBM corporation). The normality of data distribution (number of drugs per prescription, MRCI subtotal, and the total score) was tested using the Shapiro-Wilk Test. Since the data was not normally distributed $(\mathrm{p}<0.05)$ the median values of MRCI scores were compared between groups (pediatric versus geriatrics, male versus female) using the Mann-Whitney U test. Gender distribution among the groups was compared using the Chi-square test. Correlation between the number of drugs per prescription and the MRCI score was determined by the Spearman's correlation coefficient. A p value $<0.05$ was considered statistically significant.

\section{RESULTS}

Data of 90 patients discharged from the psychiatry inpatient unit with at least one medication were studied. Of these, 40 belonged to the pediatric age group. Gender distribution of patients in both the groups did not differ significantly.

Patients included in the study were on different psychotropic medications for various indications as well as on medications for comorbidities. The number of medications each patient received, ranged from one to eight in the pediatric group, whereas in the geriatric group the upper limit was eleven drugs per prescription. In the pediatric age group, the majority of the patients $(60 \%)$ received two or less drugs per prescription. In the geriatric age group, most of the patients (90\%) received more than two drugs on hospital discharge (Table 1).

Considering the entire study sample, the total MRCI score ranged from 2 to 40 , with a median value of 10 . Owing to the extremes of age-groups of the patients included, we considered the median for comparison between groups and not the mean. Table 2 shows the number of drugs per prescription, the MRCI scores for sections $\mathrm{A}, \mathrm{B}, \mathrm{C}$ and the total MRCI scores (Median and interquartile range) based on the age categories as well as for the entire study sample.

The presence of any difference in the MRCI scores between genders within each group was determined. In the pediatric group, there were 20 male and 20 female children each. The geriatric group was composed of 29 males and 21 females. In the pediatric group, the total MRCI score as well as the individual components did not vary significantly between genders. However, in the geriatric age group, a statistically significant difference was seen in the total score and the individual components except MRCI (C) with the scores being higher in male patients (Total score, $\mathrm{U}=140, \mathrm{p}=0.014$ ) (Table 3).

A strong positive correlation was seen between the number of drugs prescribed and the corresponding MRCI score. The correlation was significant in the paediatric $\left(\mathrm{r}_{\mathrm{s}}(38)=0.944, \mathrm{p}<0.001\right)$ as well as the geriatric group $\left(\mathrm{r}_{\mathrm{s}}(48)=0.866, \mathrm{p}<0.001\right)$.

\section{DISCUSSION}

This study examined the complexity of medication regimen prescribed to pediatric and geriatric patients with psychiatric disorders at the time of hospital discharge using the MRCI instrument. The MRCI takes into consideration the pharmaceutical form of the medication prescribed, the frequency of dosing, and any additional dosing instructions given to the patient. The latter two factors are important since more number of drugs per prescription may not always imply a complex prescription or worse outcome. ${ }^{14}$ Hence the MRCI provides for an all-round assessment of the factors associated with comprehension and compliance with the prescription advice. ${ }^{11-15}$ The median number of drugs that each patient received on hospital discharge in the pediatric group was two while that in the geriatric group was five $(p<0.001)$. The median MRCI score was significantly higher in the geriatric age group (15.5) in comparison to the pediatric group $(7.5)(\mathrm{p}<0.001)$. These findings are similar to those reported in a study among outpatients of a public hospital wherein the average MRCI score was $8.83 \pm 3.971$ in the age group of $0-19$ years, and $19.28 \pm 8.452$ in the age group of $60-69$ years. ${ }^{16}$ Similarly, in a study of the complexity of medication regimen in institutionalized elderly patients, the total MRCI score was $18.2 \pm 9 .{ }^{14}$ The total MRCI score reported in a study of geriatric depression cohort was $25.44 \pm 11.67$ with the average number of drugs per prescription being 12.1 (range, 3-26).$^{17}$

Taking into consideration the individual components of the MRCI score, it was seen that the dosing frequency (MRCI section B) contributed to the final score more than the other components. This is similar to reports from other studies. ${ }^{15-17}$ However, the studies differ with regard to the contribution of section $\mathrm{A}$ and $\mathrm{C}$ towards the final score. ${ }^{15-17}$ We also assessed if gender was a factor that affected the number of drugs a patient received and if the MRCI score varied across genders. In the pediatric age group, the number of drugs prescribed and the MRCI score did not differ significantly between the genders. However, the MRCI score significantly varied across genders in the geriatric age group with the score being higher in males. This is in contrast to the observations from other studies in institutionalized elderly inpatients where female gender was associated with a higher MRCI score. ${ }^{15-18}$ The difference is likely due to the different study setting and disease conditions studied.

Our results showed a strong positive correlation between the number of drugs prescribed per prescription and the MRCI score. While a number of studies have taken the number of drugs prescribed as a simple measure of medication regimen complexity the MRCI provides for a more comprehensive approach taking into consideration all the relevant aspects of a prescription. ${ }^{11-14}$ The usefulness of medication count and the MRCI score as independent measures is also dependent on the outcome of interest.

Prescriptions with higher medication regimen complexity found in our study can potentially lead to non-compliance. ${ }^{19}$ An inverse correlation has been demonstrated between treatment adherence after hospital discharge and the MRCI score. ${ }^{14}$ The success of any treatment regimen depends to a large extent on the patients' compliance to the prescription. ${ }^{20}$ Also, the risk of adverse effects occurring may also be higher. ${ }^{21}$ Identifying such prescriptions and attempting to simplify the medication regimen, wherever possible, could result in higher patient compliance and thereby better health outcomes. Our study was an attempt to identify the potential target areas wherein a suitable intervention could be made to simplify the treatment regimens. To the best knowledge of the authors, this is the first study to report the MRCI scores in psychiatry patients at extremes of age. Our study has several limitations. Considering that the study was carried out in a tertiary care setting in patients with 
Table 1: Number of drugs per prescription during hospital discharge in pediatric and geriatric psychiatry patients

\begin{tabular}{ccc}
\hline $\begin{array}{c}\text { Number of drugs per } \\
\text { prescription }\end{array}$ & $\begin{array}{c}\text { Pediatric group }(\mathrm{N}=40) \\
\mathrm{n}(\%)\end{array}$ & $\begin{array}{c}\text { Geriatric group }(\mathrm{N}=50) \\
\mathrm{n}(\%)\end{array}$ \\
\hline $0-2$ & $24(60 \%)$ & $05(10 \%)$ \\
$3-6$ & $14(35 \%)$ & $34(68 \%)$ \\
$>6$ & $02(5 \%)$ & $11(22 \%)$ \\
\hline
\end{tabular}

\begin{tabular}{|c|c|c|c|c|c|c|c|}
\hline \multirow[t]{3}{*}{$\begin{array}{c}\text { MRCI Index } \\
\text { (Components) }\end{array}$} & \multirow{2}{*}{\multicolumn{2}{|c|}{$\begin{array}{c}\begin{array}{c}\text { Pediatric } \\
(n=40)\end{array} \\
\mathrm{MRCl} \text { score }\end{array}$}} & \multirow{2}{*}{\multicolumn{2}{|c|}{$\begin{array}{c}\begin{array}{c}\text { Geriatric } \\
(n=50)\end{array} \\
\text { MRCI score }\end{array}$}} & \multirow[t]{3}{*}{$\begin{array}{c}\text { Mann Whitney } U \text {, } \\
\text { p value }\end{array}$} & \multirow{2}{*}{\multicolumn{2}{|c|}{$\begin{array}{c}\begin{array}{c}\text { Total } \\
(\mathrm{n}=90)\end{array} \\
\mathrm{MRCl} \text { score }\end{array}$}} \\
\hline & & & & & & & \\
\hline & Median (IQR) & Min - Max & Median (IQR) & Min - Max & & Median (IQR) & Min - Max \\
\hline Number of drugs & $2(1-4)$ & $1-9$ & $5(4-7)$ & $1-13$ & $349, \mathrm{p}<0.001^{*}$ & $4(2-6)$ & $1-13$ \\
\hline MRCI (A) & $1(1-1)$ & $1-7$ & $1(1-3)$ & $1-8$ & $816, \mathrm{p}=0.04^{*}$ & $1(1-1)$ & $1-8$ \\
\hline MRCI (B) & $3.5(2-5)$ & $1-11$ & $7.5(5-10)$ & $1-18$ & $406, \mathrm{p}<0.001^{*}$ & $5(2-9)$ & $1-18$ \\
\hline MRCI (C) & $3(2-5)$ & $0-8$ & $6(4-8)$ & $1-17$ & $473.5, \mathrm{p}<0.001^{*}$ & $5(2-7)$ & $0-17$ \\
\hline Total Score & $7.5(5-10)$ & $2-23.5$ & $15.5(10-21)$ & $3-40$ & $456.5, \mathrm{p}<0.001^{*}$ & $10(6-17)$ & $2-40$ \\
\hline
\end{tabular}

${ }^{*} \mathrm{p}<0.05$, statistically significant; IQR - interquartile range; Min - minimum; Max - maximum

Table 3: Gender based comparison of the Medication Regimen Complexity Index scores of hospital discharge prescriptions for pediatric and geriatric psychiatry patients

\begin{tabular}{|c|c|c|c|c|c|c|}
\hline \multirow{3}{*}{$\begin{array}{c}\text { MRCI Index } \\
\text { (Components) }\end{array}$} & \multicolumn{6}{|c|}{ Median MRCI Score } \\
\hline & \multicolumn{2}{|c|}{$\begin{array}{l}\text { Pediatric Group } \\
\qquad(n=40)\end{array}$} & \multirow{2}{*}{$p$ value } & \multicolumn{2}{|c|}{$\begin{array}{l}\text { Geriatric Group } \\
\qquad(n=50)\end{array}$} & \multirow{2}{*}{$p$ value } \\
\hline & $\begin{array}{c}\text { Male } \\
(n=20)\end{array}$ & $\begin{array}{l}\text { Female } \\
(n=20)\end{array}$ & & $\begin{array}{c}\text { Male } \\
(n=29)\end{array}$ & $\begin{array}{l}\text { Female } \\
(n=21)\end{array}$ & \\
\hline Drug Number & 2.5 & 2 & 0.602 & 6 & 5 & $0.016^{*}$ \\
\hline MRCI (A) & 1 & 1 & 0.183 & 1 & 1 & $0.031^{*}$ \\
\hline MRCI (B) & 3 & 3.5 & 0.841 & 9 & 5 & $0.018^{*}$ \\
\hline MRCI (C) & 3.5 & 3 & 0.925 & 7 & 5 & 0.057 \\
\hline Total Score & 7.5 & 7.5 & 0.758 & 17 & 13 & $0.014^{*}$ \\
\hline
\end{tabular}

${ }^{*} \mathrm{p}<0.05$, statistically significant

psychiatric morbidity the findings cannot be generalized to other clinical areas. The sample size was also limited. We have reported the median values of MRCI since the data was not normally distributed. However, other similar studies with which comparison has been made above have reported the mean values. Therefore the values are to be interpreted and compared with caution. Importantly, a low MRCI score does not mean that the prescription is rational nor does it ensure the absence of drug interactions. Hence no conclusion can be reached with regard to the rationality of the prescriptions studied.

\section{CONCLUSION}

While polypharmacy is of concern across all age groups, our study showed that the medication regimen complexity in significantly higher in the geriatric age group. A gender difference in the MRCI scores was seen in the geriatric age group with higher scores seen in males. The presence of psychiatric morbidity further complicates the issue of medication management. Hence, special attention is required in case of geriatric psychiatry patients to simplify their medication regimen at the time of hospital discharge in order to ensure better compliance.

Funding: No funding was received for this study.

\section{CONFLICT OF INTEREST}

No conflict of interest.

\section{ABBREVIATION USED}

MRCI: Medication Regimen Complexity Index; ICD-10: International Statistical Classification of Disease and Related Health Problems, Tenth revision; SPSS: Statistical Package for the Social Sciences.

\section{REFERENCES}

1. Comer JS, Olfson M, Mojtabai R. National trends in child and adolescent psychotropic polypharmacy in office-based practice, 1996-2007. Journal of the American Academy of Child \& Adolescent Psychiatry. 2010;49(10):1001-10. https://doi org/10.1016/j.jaac.2010.07.007; PMid:20855045 PMCid:PMC2952543.

2. Jameel F, Kamath A, Bhat SM, Bairy LK. A Descriptive Study of Use of Psycho- 
tropic Drugs in Child and Adolescent Psychiatric IIIness in an Inpatient Facility. Journal of Clinical and Diagnostic Research. 2012;6(3):431-6.

3. Vidal X, Agustí A, Vallano A, Formiga F, Moyano AF, García J, et al. Elderly patients treated with psychotropic medicines admitted to hospital: associated characteristics and inappropriate use. European journal of clinical pharmacology. 2016;72(6):755-64.v https://doi.org/10.1007/s00228-016-2032-2; PMid:26944419.

4. Tiihonen J, Suokas JT, Suvisaari JM, Haukka J, Korhonen P. Polypharmacy with antipsychotics, antidepressants, or benzodiazepines and mortality in schizophrenia. Archives of general psychiatry. 2012;69(5):476-83. https://doi. org/10.1001/archgenpsychiatry.2011.1532; PMid:22566579.

5. Kingsbury SJ, Yi D, Simpson GM. Psychopharmacology: rational and irrational polypharmacy. Psychiatric Services. 2001 Aug;52(8):1033-6. https://doi. org/10.1176/appi.ps.52.8.1033; PMid:11474046.

6. Kukreja S, Kalra G, Shah N, Shrivastava A. Polypharmacy in psychiatry: a review. Mens sana monographs. 2013;11(1):82. https://doi.org/10.4103/0973-1229.104497; PMid:23678240 PMCid:PMC3653237.

7. Prakash OM. Poly-pharmacy in psychiatry: a debatable contemporary practice? Not much evidence: letter to the editor. African journal of psychiatry. $2011 ; 14(5): 410$.

8. Kripalani S, Price M, Vigil V, Epstein KR. Frequency and predictors of prescription-related issues after hospital discharge. Journal of hospital medicine. 2008;3(1):12-9. https://doi.org/10.1002/jhm.248; PMid:18257096.

9. Jackevicius CA, Li P, Tu JV. Prevalence, predictors, and outcomes of primary nonadherence after acute myocardial infarction. Circulation. 2008;117(8):1028-36. https://doi.org/10.1161/CIRCULATIONAHA.107.706820; PMid:18299512.

10. Stone Jr ME, Marsh J, Cucuzzo J, Reddy SH, Teperman S, Kaban JM. Factors associated with trauma clinic follow-up compliance after discharge: experience at an urban Level I trauma center. Journal of Trauma and Acute Care Surgery. 2014;76(1):185-90. https://doi.org/10.1097/TA.0b013e3182aafcd5; PMid:24368377

11. George J, Phun YT, Bailey MJ, Kong DC, Stewart K. Development and validation of the medication regimen complexity index. Annals of Pharmacotherapy. 2004;38(9):1369-76. https://doi.org/10.1345/aph.1D479; PMid:15266038.

12. Elliott RA, O'Callaghan CJ. Impact of hospitalisation on the complexity of older patients' medication regimens and potential for regimen simplification.
Journal of Pharmacy Practice and Research. 2011;41(1):21-5. https://doi. org/10.1002/j.2055-2335.2011.tb00060.x.

13. Hirsch JD, Metz KR, Hosokawa PW, Libby AM. Validation of a Patient-Level Medication Regimen Complexity Index as a Possible Tool to Identify Patients for Medication Therapy Management Intervention. Pharmacotherapy: The Journal of Human Pharmacology and Drug Therapy. 2014;34(8):826-35. https://doi. org/10.1002/phar.1452; PMid:24947636 PMCid:PMC4260116.

14. Mansur N, Weiss A, Beloosesky Y. Looking beyond polypharmacy: quantification of medication regimen complexity in the elderly. The American journal of geriatric pharmacotherapy. 2012;10(4):223-9. https://doi.org/10.1016/j.amjopharm.2012.06.002; PMid:22749668.

15. Advinha AM, de Oliveira-Martins S, Mateus V, Pajote SG, Lopes MJ. Medication regimen complexity in institutionalized elderly people in an aging society. International journal of clinical pharmacy. 2014;36(4):750-6. https://doi.org/10.1007/ s11096-014-9963-4; PMid:24906719.

16. Oosthuizen F, Dhoodhat E, Kazi S, Masondo B, Omarjee N, Sacoor Z, Shaik F, Singh D. Assessing the complexity of medicine regimens A pilot study. African Journal of Pharmacy and Pharmacology. 2011;5(16):1863-6. https://doi. org/10.5897/ajpp11.276.

17. Libby AM, Fish DN, Hosokawa PW, Linnebur SA, Metz KR, Nair KV, Saseen JJ, Griend JP, Vu SP, Hirsch JD. Patient-level medication regimen complexity across populations with chronic disease. Clinical therapeutics. 2013;35(4):385-98. https://doi.org/10.1016/j.clinthera.2013.02.019; PMid:23541707.

18. Rettig SM, Wood Y, Hirsch JD. Medication regimen complexity in patients with uncontrolled hypertension and/or diabetes. Journal of the American Pharmacists Association.2013;53(4):427-31. https://doi.org/10.1331/JAPhA.2013.13003; PMid:23892818.

19. Roy NT, Sajith M, Bansode MP. Assessment of Factors Associated with Low Adherence to Pharmacotherapy in Elderly Patients. Journal of Young Pharmacists. 2017 Apr 1;9(2):272. https://doi.org/10.5530/jyp.2017.9.53.

20. Brown MT, Bussell JK. Medication adherence: WHO cares?. InMayo Clinic Proceedings 2011(Vol. 86, No. 4, pp. 304-314). Elsevier.

21. Makaryus AN, Friedman EA. Patients' understanding of their treatment plans and diagnosis at discharge. InMayo Clinic Proceedings 2005 (Vol. 80, No. 8, pp 991-994). Elsevier.

Article History: Submission Date : 18-02-2017; Revised Date : 16-04-2017; Acceptance Date : 04-05-2017.

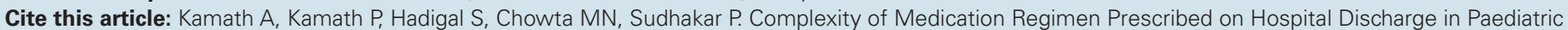
and Geriatric Patients with Psychiatric Disorder. J Young Pharm. 2017;9(3): 395-8. 